The University of Manchester

\title{
The Use Of Glucagon In The Treatment Of Hypoglycaemia Due To Congenital Hyperinsulinism
}

\author{
C Jadawji, M S Estebanez, R Padidela, L Bowden, L Rigby, J Kinzell, K E Cosgrove, M J Dunne, I Banerjee
}

\section{Background}

- Congenital Hyperinsulinism (CHI) can cause severe hypoglycaemia with consequent adverse neurodevelopment

- Continuous Glucagon Infusion (CGI) has been utilised to achieve glycaemic stability - its efficacy has not been systematically reported

\section{Aims}

- To review the efficacy of CGI and assess the complications associated with glucagon infusion

\author{
Methods \\ - A retrospective review was conducted, in a cohort of 31 children over a 5 year period \\ - The efficacy of CGI was reviewed by assessing the impact on the glucose infusion rate (GIR) within 48 hours of treatment \\ - Factors affecting severity of CHI: K-ATP channel gene mutations, diazoxide unresponsiveness, requirement for second-line treatment \\ with octreotide and sub-total pancreatectomy were also assessed in relation to CGI
}

\section{Results}

- CGI in a dose of $5 \mathrm{mcg} / \mathrm{kg} /$ hour administered either intravenously $(n=29)$ or subcutaneously $(n=2)$ reduced GIR from a mean (interquartile range) of 15.9 (8.1) to 11.5 (4.9) $\mathrm{mg} / \mathrm{kg} /$ minute. See Fig. 1

- Reduction independent of factors affecting the severity of $\mathrm{CHI}$ - Maximum dose required to achieve euglycaemia [12.4 (15) $\mathrm{mcg} / \mathrm{kg} / \mathrm{hour}$ ] was directly correlated with the pre-glucagon GIR $\left[R^{2}=0.7, p<0.001\right]$

- Duration of 33 (30) days of CGI helped maintaining euglycaemia in addition to therapy with diazoxide or octreotide $[n=16]$

Fig. 1: A Box-plot demonstrating the difference in the GIR, both pre-glucagon and 48 hours post-glucagon administration

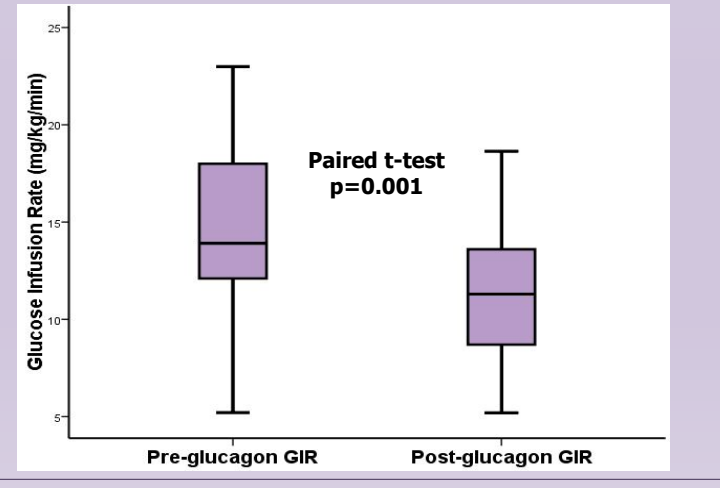

\section{Complications}

- 1 patient developed a necrolytic migratory erythema (NME) Resolved once CGI discontinued. Refer to Fig. 2

- Crystallization of glucagon can lead to line obstruction, though not reported in this study

Fig. 2: Images depicting NME after administration of subcutaneous CGI
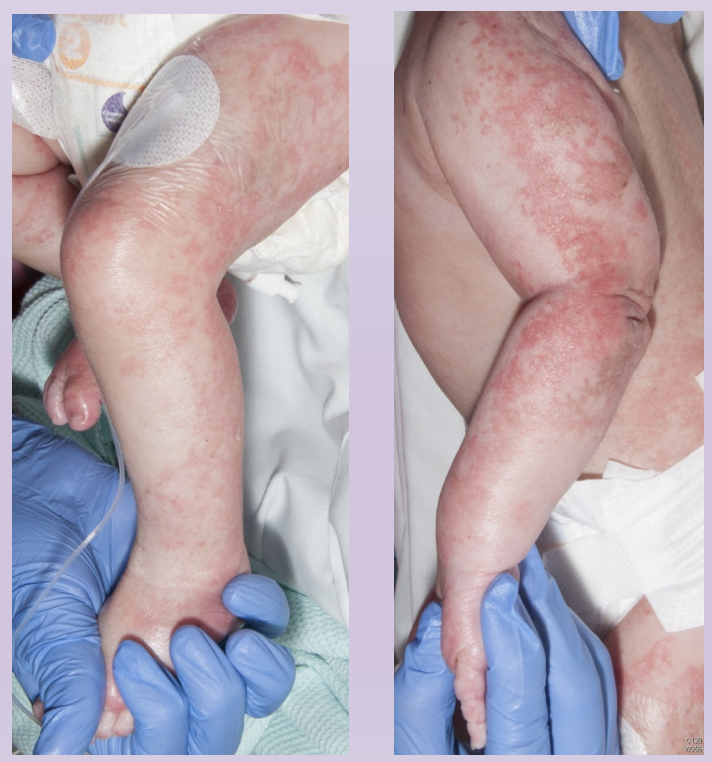

\section{Conclusions}

- CGI is effective in reducing GIR in patients with $\mathrm{CHI}$ in the short and long term management

- Generally safe, NME is a possible adverse event with CGI treatment 